\title{
Mossy Cells in the Dorsal and Ventral Dentate Gyrus Differ in Their Patterns of Axonal Projections
}

\author{
Carolyn R. Houser, ${ }^{1,3}$ Zechun Peng, ${ }^{1}{ }^{\odot}$ Xiaofei Wei, ${ }^{2}$ Christine S. Huang, ${ }^{1}$ and ${ }^{\circledR}$ Istvan Mody ${ }^{2,3}$ \\ ${ }^{1}$ Department of Neurobiology, ${ }^{2}$ Department of Neurology, and ${ }^{3}$ Brain Research Institute, David Geffen School of Medicine at the University of \\ California, Los Angeles, Los Angeles, California 90095
}

Mossy cells (MCs) of the dentate gyrus (DG) are a major group of excitatory hilar neurons that are important for regulating activity of dentate granule cells. MCs are particularly intriguing because of their extensive longitudinal connections within the DG. It has generally been assumed that MCs in the dorsal and ventral DG have similar patterns of termination in the inner one-third of the dentate molecular layer. Here, we demonstrate that axonal projections of MCs in these two regions are considerably different. MCs in dorsal and ventral regions were labeled selectively with Cre-dependent eYFP or mCherry, using two transgenic mouse lines (including both sexes) that express Cre-recombinase in MCs. At four to six weeks following unilateral labeling of MCs in the ventral DG, a dense band of fibers was present in the inner one-fourth of the molecular layer and extended bilaterally throughout the rostral-caudal extent of the DG, replicating the expected distribution of MC axons. In contrast, following labeling of MCs in the dorsal DG, the projections were more diffusely distributed. At the level of transfection, fibers were present in the inner molecular layer, but they progressively expanded into the middle molecular layer and, most ventrally, formed a distinct band in this region. Optical stimulation of these caudal fibers expressing ChR2 demonstrated robust EPSCs in ipsilateral granule cells and enhanced the effects of perforant path stimulation in the ventral DG. These findings suggest that MCs in the dorsal and ventral DG differ in the distribution of their axonal projections and possibly their function.

Key words: associational pathway; commissural pathway; dentate granule cells; hilus; hippocampus; mossy cells

\section{Significance Statement}

Mossy cells (MCs), a major cell type in the hilus of the dentate gyrus (DG), are unique in providing extensive longitudinal and commissural projections throughout the DG. Although it has been assumed that all MCs have similar patterns of termination in the inner molecular layer of the DG, we discovered that the axonal projections of dorsal and ventral MCs differ. While ventral MC projections exhibit the classical pattern, with dense innervation in the inner molecular layer, dorsal MCs have a more diffuse distribution and expand into the middle molecular layer where they overlap and interact with innervation from the perforant path. These distinct locations and patterns of axonal projections suggest that dorsal and ventral MCs may have different functional roles.

\section{Introduction}

Mossy cells (MCs) are a prominent group of glutamatergic neurons in the hilus of the dentate gyrus (DG) that are ideally positioned to regulate activity of dentate granule cells. They receive

\footnotetext{
Received Sep. 16, 2020; revised Nov. 8, 2020; accepted Nov. 20, 2020.

Author contributions: C.R.H., Z.P., and I.M. designed research; Z.P., X.W., and C.S.H. performed research; C.R.H., Z.P., X.W., C.S.H., and I.M. analyzed data; C.R.H. and I.M. wrote the paper.

This work was supported by National Institutes of Health National Institute of Neurological Disorders and Stroke Grants NS102608 and NS099137 (to C.R.H.) and NS030549 and AG050474 (to I.M.). We thank Dr. Kazu Nakazawa for providing material for re-derivation of the Calcrl-Cre mouse line, Dr. Karl Deisseroth for making reagents available through Addgene, and the Penn Vector Core in the School of Medicine Gene Therapy Program at the University of Pennsylvania for preparation of the ChR2-eYFP viral vector.

The authors declare no competing financial interests.

Correspondence should be addressed to Carolyn R. Houser at houser@mednet.ucla.edu.

https://doi.org/10.1523/JNEUROSCI.2455-20.2020

Copyright $\odot 2021$ the authors
}

their major inputs from dentate granule cells, semilunar granule cells, and pyramidal cells of CA3 (Amaral, 1978; Frotscher et al., 1991; Scharfman, 2007; Williams et al., 2007). MCs in turn form excitatory contacts on granule cells and interneurons and, through these connections, can exert either excitatory or inhibitory influences on dentate granule cells (Scharfman, 1995; Wenzel et al., 1997). MCs are considered to play a major role in controlling activity of granule cells and thus contribute to the processes of learning and memory, including spatial learning and pattern separation (Buckmaster and Schwartzkroin, 1994; Scharfman, 2016; Nakazawa, 2017). However, much remains to be learned about their function and related anatomic organization.

Among neurons of the DG, MCs are unique in forming longitudinal connections within the dentate, expanding beyond the lamella in which they are located and forming links with neurons 
in distant levels of the DG (Buckmaster et al., 1996). By linking neurons at different levels, MCs can transform the two-dimensional DG, based on its primarily lamellar organization, into a functional three-dimensional unit (Amaral and Witter, 1989). Understanding these longitudinal connections has become increasingly important as more is learned about the functional subdivisions within the hippocampus and DG (Bannerman et al., 2004; Kheirbek et al., 2013; Strange et al., 2014), and MCs could be critical for interconnecting these functionally distinct regions of the DG. The longitudinal connections are also important to consider as MCs can now be studied selectively in awake, behaving animals in which distant MC connections remain intact (Danielson et al., 2017; GoodSmith et al., 2017, 2019; Senzai and Buzsáki, 2017; Jung et al., 2019). Although the commissural and associational projections of the DG have been described previously in numerous anatomic studies using silver degeneration and autoradiographic tracing methods (Zimmer, 1971; Gottlieb and Cowan, 1973; Swanson et al., 1978; Laurberg and Sørensen, 1981), it has been difficult to relate the extensive axonal projections directly to the MCs of origin, because of the lack of specificity of the labeling methods. Likewise, it has not been possible to compare the projections from different groups of MCs in the same animal.

The availability of transgenic mice that express Cre-recombinase (Cre) in MCs of the DG has made it possible to label the cell bodies of MCs selectively in specific regions of the DG and study their projections. The goals of this study were to determine the distribution of MC fibers throughout the DG and compare the axonal projections of MCs of dorsal and ventral regions. In the process, we discovered that MCs in dorsal and ventral regions of the dentate have different patterns of axonal projections. These differences could potentially be associated with different functional roles. Preliminary reports of some of these findings have been presented previously in abstract form (Houser et al., 2019).

\section{Materials and Methods}

Animals

Two transgenic mouse lines that express Cre relatively selectively in MCs of the DG were used in this study. The Calcrl-Cre mouse, also referred to as $M C / C A 3-C r e$ mouse, expresses Cre under the control of the murine calcitonin receptor-like promoter and was generated and characterized by Nakazawa and colleagues (Jinde et al., 2012). Material for re-derivation of the Calcrl-Cre mice was generously provided by Nakazawa, and a breeding colony was established. These mice are now available from The Jackson Laboratory (C57BL/6N-Tg(Calcrl,cre) 4688Nkza/J, JAX stock \#023014). The Drd2-Cre mouse expresses Cre under the control of the dopamine D2 receptor promoter and was generated by Gene Expression Nervous System Atlas (GENSAT; Gong et al., 2003). Labeling patterns were characterized in detail by Gangarossa et al. (2012). Drd2-Cre mice were obtained from the Mutant Mouse Resource and Research Centers (MMRRC), Mouse Biology Program at the University of California, Davis (B6.FVB(Cg)-Tg(Drd2-cre)ER44Gsat/ Mmucd, stock \#032108-UCD).

Mice (male and female) were two to three months of age at the time of transfection and were studied at four to six weeks following transfection ( $n=14$ Calcrl-Cre mice and $n=5$ Drd2-Cre mice for anatomic studies; and $n=9$ Calcrl-Cre mice for optogenetic/electrophysiological studies). All animal use protocols conformed to the National Institutes of Health guidelines and were approved by the University of California, Los Angeles, Chancellor's Animal Research Committee.

Viral vector injections

To selectively label MCs in the hilus of the DG, Calcrl-Cre or Drd2-Cre mice were transfected with Cre-dependent double-floxed recombinant adeno-associated viral (AAV) vectors containing constructs encoding either eYFP or mCherry for neuroanatomical studies or ChR2-eYFP for optogenetic/electrophysiological studies. The viral vectors for eYFP (AAV DJ-EF1a-DIO eYFP) and mCherry (AAV DJ-EFla-DIO mCherry) were obtained from the Neuroscience Gene Vector and Virus Core, Stanford University. The construct for ChR2-eYFP, 2/9.EF1a.DIO.hChR2(H134R)EYFP.WPRE.HGh (Addgene plasmid \#20298) was kindly made available by Karl Deisseroth, and the AAV vector was produced by the Penn Vector Core in the School of Medicine Gene Therapy Program at the University of Pennsylvania.

For transfections, mice were anesthetized with isoflurane, and Credependent viral vectors were stereotaxically injected in the dorsal and/or ventral DG with a Nanoject II injector (Drummond Scientific), using glass pipettes. A small animal stereotaxic instrument with digital display console (Model 940; Kopf Instruments) was used for precise positioning of the pipette in the hilus. For neuroanatomical studies, injections were made unilaterally in the hilus (right side), at either rostral or caudal levels (eYFP for each) or at both locations in the same animal (mCherry rostral; eYFP caudal). The goal was to label the rostral or caudal group of MCs as completely as possible and avoid extensive overlap of labeling in the middle region of the DG in double labeling studies. Optimal stereotaxic coordinates were experimentally determined. Rostral injections were made at two sites in close proximity to each other [-1.8 anteroposterior (AP), 1.0 mediolateral (ML), 2.2 dorsoventral (DV); and -2.0 AP, 1.2 ML, 2.1 DV; Fig. 1A-C; Paxinos and Franklin, 2019]. Caudal injections were made at two sites (-3.5 AP, 2.6 ML, 3.0 DV; and -3.8 AP, 2.6 ML, 3.7 DV; Fig. $1 A, D, E)$. The injection volumes were $69-92 \mathrm{nl}$ at each site (23-nl increments $\times$ three to four injections). Following the injection at each anteroposterior location, the pipette was left in position for $5 \mathrm{~min}$ before it was slowly retracted from the brain. Animals for the electrophysiological studies were similarly transfected for ChR2-eYFP at rostral sites only.

\section{Tissue preparation for light microscopy}

All mice used for neuroanatomical studies were deeply anesthetized with Fatal-Plus ( $90 \mathrm{mg} / \mathrm{kg}$, i.p.) and perfused transcardially with $4 \%$ paraformaldehyde in $0.12 \mathrm{M}$ phosphate buffer ( $\mathrm{pH} 7.3$ ). After $1 \mathrm{~h}$ at $4^{\circ} \mathrm{C}$, brains were removed and postfixed for $1 \mathrm{~h}$. After rinsing, brains were cryoprotected in a $30 \%$ sucrose solution overnight, embedded in OCT compound (Sakura Finetek), frozen on dry ice, and sectioned at $30 \mu \mathrm{m}$ with a cryostat (CM 3050S, Leica Microsystems). For detailed comparisons of $\mathrm{MC}$ projections at dorsal and ventral levels, brains were sectioned coronally through the rostral (dorsal) half and then horizontally through the caudal (ventral) half of the hippocampus (Fig. 1A). To determine the patterns of labeling in sections cut in the same plane throughout the DG, the hippocampus was removed, elongated, and sectioned transversely through the entire length of the DG. To demonstrate the labeling patterns in typical coronal sections, some brains were sectioned coronally through the entire hippocampus.

Sections at $300-\mu \mathrm{m}$ intervals through the entire length of the DG were mounted on slides for confocal microscopy without further enhancement of eYFP or mCherry, as described previously (Peng et al., 2013). Adjacent series of sections were stained with cresyl violet for general histology. For some studies, additional sections were labeled with 4',6-diamidino-2-phenylindole (DAPI) to demonstrate the granule cell layer. These sections were mounted on slides; NucBlue Fixed Cell Stain Ready Probes, DAPI Special Formulation, was applied to the tissue (Invitrogen); and slides were coverslipped with DAPI Fluoromount-G mounting media (SouthernBiotech).

\section{Antisera}

To characterize the eYFP-labeled neurons in the hilus, sections were double labeled for either GluA2, an AMPA receptor subunit that is expressed in most principal cells of the telencephalon, including MCs, but not in GABA neurons in the hippocampus (Leranth et al., 1996; Petralia et al., 1997), or calretinin, an established marker of a subgroup of MCs (Liu et al., 1996; Blasco-Ibáñez and Freund, 1997). A rabbit polyclonal antiserum to GluA2 (previously referred to as GluR2; Millipore, $\mathrm{AB1768)}$ and a mouse monoclonal antibody to calretinin (Millipore, MAB1568) were used for immunofluorescence labeling. The specificity 

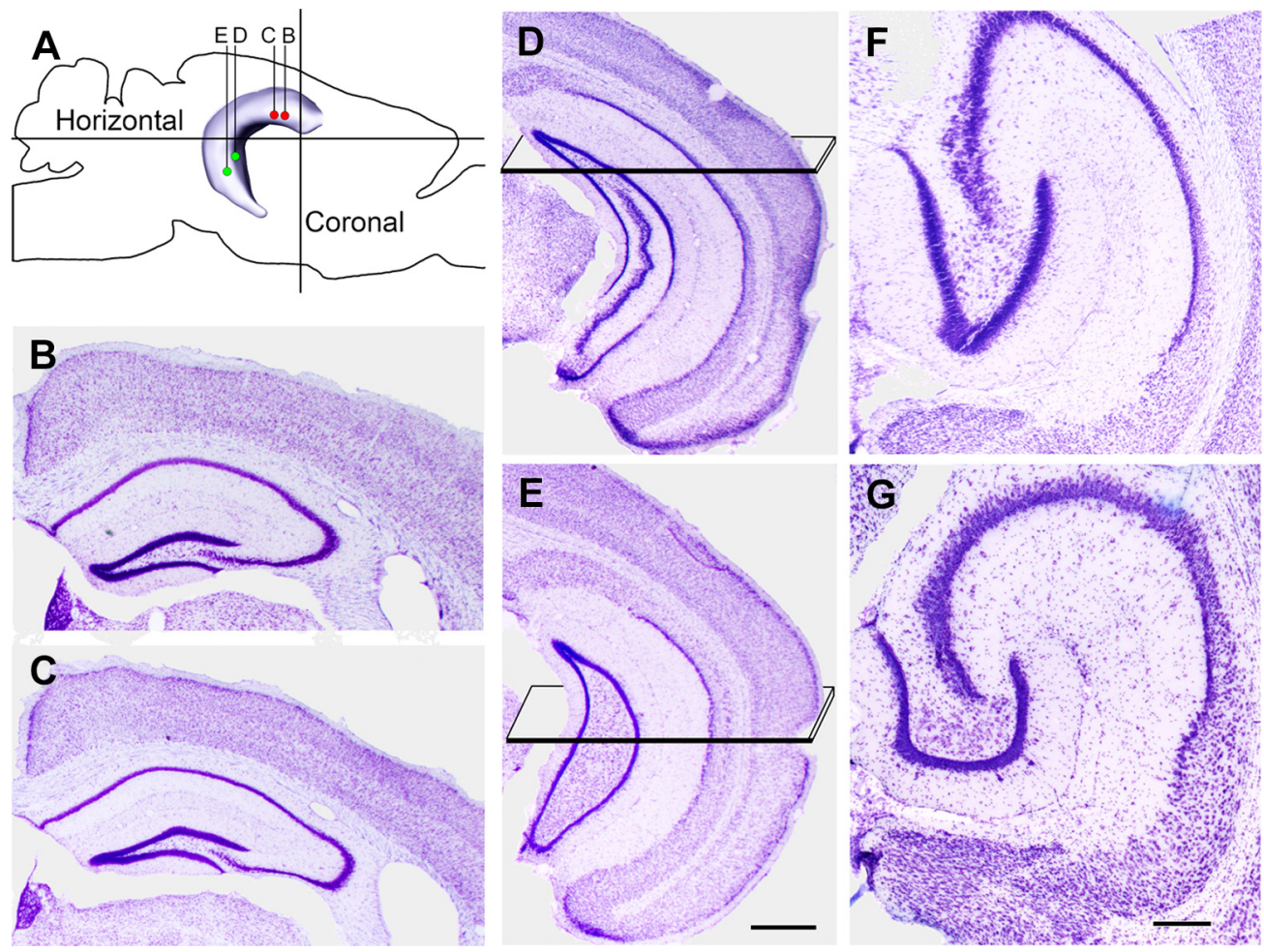

Figure 1. Locations of the transfections and planes of section used for histologic analysis are illustrated diagrammatically and in Nissl-stained sections of the hippocampus. $\boldsymbol{A}$, Transfections were made at two sites in the rostral (dorsal) and two sites in the caudal (ventral) DG. In double-labeled experiments, transfections for mCherry (red dots) were made rostrally, and those for eYFP (green dots) were made caudally. $\boldsymbol{B}-\boldsymbol{E}$, AP levels of the transfections are illustrated in coronal sections, progressing from the most rostral (B) to most caudal $(\boldsymbol{E})$, and correspond to coordinates described in the text. Planes in $\boldsymbol{D}, \boldsymbol{E}$ indicate the locations of the horizontal sections. $\boldsymbol{F}, \boldsymbol{G}$, For histologic analysis, the ventral hippocampus was sectioned in the horizontal plane, with the section in $\boldsymbol{F}$ corresponding to the region transected by the plane in $\boldsymbol{D}$, and the section in $\boldsymbol{G}$ corresponding to the region transected by the plane in $\boldsymbol{E}$. When sectioned in the horizontal plane, the rostral (anterior) region of the ventral $D G$ has an elongated shape $(\boldsymbol{F})$, and the more caudal region assumes a $($-shape $(\boldsymbol{G})$. The image of the hippocampus $(\boldsymbol{A})$ and planes of section for the horizontal images $(\boldsymbol{F}, \boldsymbol{G})$ are based on data from the Allen Brain Atlas, Explorer 2. Scale bars: $500 \mu \mathrm{m}(\boldsymbol{B}-\boldsymbol{E})$ and $200 \mu \mathrm{m}(\boldsymbol{F}, \boldsymbol{G})$.

of these antisera has been demonstrated previously (Sans et al., 2003; Fuentes-Santamaria et al., 2005; Jiao and Nadler, 2007).

\section{Double immunofluorescence labeling}

For double-labeling studies, either GluA2 or calretinin was localized with immunofluorescence methods in sections from animals previously transfected for eYFP. For both sets of studies, sections were incubated for $2 \mathrm{~h}$ in $10 \%$ normal goat serum to block nonspecific binding sites and $0.3 \%$ Triton X-100 to increase reagent penetration. Sections were incubated in primary antisera (GluA2 1:100; or calretinin 1:20,000) for $72 \mathrm{~h}$. Sections were then incubated in secondary antiserum (goat anti-rabbit or goat anti-mouse IgG conjugated to Alexa Fluor 555; Invitrogen) for 4 $\mathrm{h}$ at room temperature, mounted on slides, and coverslipped with antifade medium ProLong Diamond (Invitrogen).

\section{Analysis of morphologic data}

Fluorescence-labeled sections were scanned with an LSM 880 (Carl Zeiss) confocal microscope, and confocal images were analyzed with Zen 2, black edition, software (Carl Zeiss). For detailed analysis of eYFP or mCherry in the hilus, confocal Z-stack images $(1-\mu \mathrm{m}$ optical thickness) were acquired (excitation spectra 488 and $555 \mathrm{~nm}$ ). In sections with both eYFP and mCherry labeling in the same section, optical slices were scanned separately for each label, alternating between the two channels in each section through the Z-stack. For comparing labeling at different levels of the DG or between the two sides of the same section, sections were imaged with identical conditions. All eYFP and mCherry labeling described in this study was from the transfection-induced expression of the fluorescent proteins and was not enhanced by immunofluorescent labeling. In a subset of animals with double labeling, the width of the projections from dorsal and ventral MCs was measured in the suprapyramidal (enclosed) blade of the DG at four representative levels (two dorsal and two ventral) using the measuring tool in the Zen (black edition) software. The widths of the molecular layer and each projection were determined (three measurements of each projection at each level in four animals), and the percentages of the molecular layer occupied by the labeled bands were calculated. Measurements were made bilaterally at dorsal levels but only ipsilaterally at ventral levels as variable labeling on the contralateral side limited the accuracy of the measurements.

Terminology and planes of section for neuroanatomical studies Despite interest in the characteristics of the dorsal and ventral hippocampus, there is currently no precise way to distinguish these regions anatomically. In this study, the dorsal DG was defined operationally as the rostral (anterior or septal) one-half of the DG, and the ventral dentate was defined as the caudal (posterior or temporal) one-half, in relation to the entire longitudinal axis of the DG. In coronal sections, the dorsal dentate corresponded to AP coordinates -1.0 to -2.5 (in relation to bregma), and ventral dentate corresponded to coordinates -2.7 to -4.0 (Paxinos and Franklin, 2019). To allow the most complete analysis of both regions, dorsal regions of the DG were studied in the coronal plane while ventral regions were studied in the horizontal plane (Fig. $1 A-G$ ). In photomicrographs of sections in the horizontal plane, the more rostral (anterior) regions of the ventral DG have an elongated shape while more caudal (posterior) regions assume a C-shape with an expanded hilus (Fig. 1F,G). Locations of the horizontal sections in relation to coronal sections through the hippocampus are illustrated in Figure $1 D-G$.

Hippocampal slice preparation for electrophysiology

Briefly, mice were anesthetized with isoflurane and decapitated following University of California, Los Angeles, Chancellor's Animal Research Committee protocol. Horizontal $350-\mu \mathrm{m}$ slices were cut on a Leica VT1000S vibratome in ice-cold $N$-methyl-D-glutamine (NMDG)-based 
HEPES-buffered solution, containing the following: $135 \mathrm{~mm}$ NMDG, 10 mм D-glucose, $4 \mathrm{~mm} \mathrm{MgCl}$, $0.5 \mathrm{~mm} \mathrm{CaCl}$, $1 \mathrm{~mm} \mathrm{KCl,} 1.2 \mathrm{~mm} \mathrm{KH}_{2} \mathrm{PO}_{4}$, $20 \mathrm{~mm}$ HEPES, and $27 \mathrm{~mm}$ sucrose (bubbled with $100 \% \mathrm{O}_{2}, \mathrm{pH} 7.4,290-$ $300 \mathrm{mOsm} / \mathrm{l})$. Then, slices were incubated at $32^{\circ} \mathrm{C}$ in a reduced sodium artificial CSF (ACSF), containing the following: $85 \mathrm{~mm} \mathrm{NaCl}, 25 \mathrm{~mm} \mathrm{D}-$ glucose, $55 \mathrm{~mm}$ sucrose, $2.5 \mathrm{~mm} \mathrm{KCl}, 1.25 \mathrm{~mm} \mathrm{NaH}_{2} \mathrm{PO}_{4}, 0.5 \mathrm{~mm} \mathrm{CaCl}_{2}$, $4 \mathrm{~mm} \mathrm{MgCl}_{2}$, and $26 \mathrm{~mm} \mathrm{NaHCO}_{3}$, pH 7.3-7.4 when bubbled with $95 \%$ $\mathrm{O}_{2}, 5 \% \mathrm{CO}_{2}$. After $30 \mathrm{~min}$, low sodium ACSF was substituted for normal ACSF at room temperature, containing the following: $126 \mathrm{~mm} \mathrm{NaCl}, 10$ mM D-glucose, $2 \mathrm{~mm} \mathrm{MgCl}, 2 \mathrm{~mm} \mathrm{CaCl}, 2.5 \mathrm{~mm} \mathrm{KCl}, 1.25 \mathrm{~mm}$ $\mathrm{NaH}_{2} \mathrm{PO}_{4}, 1.5 \mathrm{~mm}$ Na pyruvate, $1 \mathrm{~mm}$ L-glutamine, and $26 \mathrm{~mm} \mathrm{NaHCO}$, pH 7.3-7.4 when bubbled with $95 \% \mathrm{O}_{2}, 5 \% \mathrm{CO}_{2}$. For recording, brain slices were transferred to a submerged recording chamber at $34^{\circ} \mathrm{C}$ and perfused at $5 \mathrm{ml} / \mathrm{min}$ with ACSF. All salts were purchased from SigmaAldrich.

\section{Patch clamp recordings}

To characterize the effects of dorsal MC projections on ventral dentate granule cells, we performed whole-cell patch clamp recordings under voltage and current clamp conditions in horizontal brain slices. We evoked EPSCs and EPSPs in granule cells by optically stimulating the MC fiber projection in hippocampal slices where no MC body labeling was present.

Slices were visualized under an IR-DIC upright microscope, and whole-cell recordings were performed with borosilicate patch pipettes (4-6 M $\Omega$ ) containing an internal solution (ICS) with the following: 140 mм Cs-met, $2 \mathrm{~mm} \mathrm{MgCl}_{2} 10 \mathrm{~mm}$ HEPES, $0.2 \mathrm{~mm}$ EGTA, $2 \mathrm{~mm} \mathrm{Na}_{2}-$ ATP, $0.2 \mathrm{~mm} \mathrm{Na}_{2}$-GTP for voltage clamp recording, and $135 \mathrm{~mm} \mathrm{~K}$-met, $5 \mathrm{~mm} \mathrm{KCl}, 2 \mathrm{~mm} \mathrm{MgCl} 2,10$ mм HEPES, 0.2 mм EGTA, 2 mм Na 2 -ATP, $0.2 \mathrm{~mm} \mathrm{Na}_{2}$-GTP for current clamp recording. The $\mathrm{pH}$ of the ICS was adjusted to 7.2 with $\mathrm{CsOH}$ or $\mathrm{KOH}$, and its osmolarity was 285-290 $\mathrm{mOsm} / \mathrm{l}$. ICS was stored at $-80^{\circ} \mathrm{C}$ and kept on ice during the experiment. Recordings were obtained using an Axopatch 200B amplifier (Molecular Devices), low-pass filtered at $5 \mathrm{kHz}$ (Bessel, 8-pole) and digitized at $10 \mathrm{kHz}$ with a National Instruments data acquisition board (BNC 2110). All data were acquired with EVAN (custom-designed LabView-based software).

\section{Stimulation}

Optogenetic stimulation was performed via an optical fiber $(200 \mu \mathrm{m}$ diameter), with its tip positioned just above the DG molecular layer. The light source consisted of a 430- to 490-nm blue diode laser (SLOC Lasers) driven by a National Instruments USB multifunction I/O device (USB 6221). The duration of light pulse was $5 \mathrm{~ms}$. The electrical stimulation was performed on the perforant path fibers located outside the hippocampal fissure. The pulse duration was $150 \mu \mathrm{s}$, the inter-pulse interval was at least $30 \mathrm{~s}$, and constant current intensity ranged between 0.1 and $1 \mathrm{~mA}$. A stimulus isolator (A365, World Precision Instruments) was the electrical source and also driven by the USB 6221. All stimulation waveforms were programmed by WinWCP (Strathclyde Electrophysiology Software).

\section{Experimental design and statistical analysis}

Twenty-one animals were used in the descriptive neuroanatomical studies (17 males and four females). In all animals, the entire length of the DG was imaged and analyzed with confocal microscopy at a minimum of $300-\mu \mathrm{m}$ intervals. Measurements of the width of labeled projections from both dorsal and ventral MCs were made in four animals (three males and one female) at four levels (three measurements at each level $=12$ measurements per level). Mean widths and standard deviations were determined with Excel 2016

For the electrophysiological studies, recordings were collected from nine mice, with four mice (three males and one female) used for voltage clamp and five mice (two males and three females) used for current clamp studies. For the measurements and analyses, evoked responses were detected and measured by EVAN (in-house LabView-based software), and the arithmetic sum of traces was determined by using Igor Pro 6.2 (WaveMetrics). All data are presented as mean \pm SEM, and cell or slice numbers are indicated. Statistical calculations and analyses were done in GraphPad Prism 6 (GraphPad) and Excel 2016, using two-tailed Fischer's exact test, Wilcoxon paired-rank test, two-tailed MannWhitney test or non-parametric Kruskal-Wallis test as indicated. Significance level was set to $p<0.05$. Exact $p$ values for significance levels are indicated in the text and/or figures. Figures were prepared using Igor Pro 6.2 and Adobe Illustrator CC 2017.

\section{Results}

MCs were specifically labeled in two transgenic mouse lines Two transgenic mouse lines that express Cre relatively selectively in MCs were transfected with Cre-dependent constructs for either fluorescent markers (eYFP or mCherry) or channelrhodopsin (ChR2) to determine the characteristics of labeled MCs and their projections within the DG.

Initial studies in both mouse lines confirmed the specificity of Cre expression in MCs throughout the rostral-caudal extent of the DG as well as the effectiveness of the transfection methods used in this study. While labeling was generally specific for MCs (Gangarossa et al., 2012; Jinde et al., 2012), each mouse line exhibited some extraneous labeling in the hippocampus. In the Calcrl-Cre mouse, CA3c pyramidal cells were also labeled in some mice, as described previously (Jinde et al., 2012). The extent of CA3c labeling varied among animals and among levels of the DG in the same animal. To reduce the possibility of CA3c labeling, we only used mice that were over two months of age at the time of transfection, as labeling of CA3c neurons decreases by eight weeks in these mice (Jinde et al., 2012). In the Drd2-Cre mouse, scattered interneurons were labeled in the DG and hippocampus in some sections, as described previously (Puighermanal et al., 2015). However, because of the size and locations of these neurons, this labeling could be distinguished from that of MCs and did not affect the major findings. Some CA3c pyramidal cell labeling was also observed occasionally in the Drd2-Cre mice, although less frequently than in the CalcrlCre mouse. Beyond these slight differences in extraneous labeling, specific labeling of MCs within the regions of transfection was extensive in both mouse lines. Importantly, both mouse lines expressed Cre in MCs throughout the DG and thus Creexpressing cells were not biased toward dorsal or ventral regions. Results from both mouse lines are described interchangeably in the following descriptions.

\section{Dorsal and ventral MCs differ in their morphologic and neurochemical characteristics}

At four to six weeks posttransfection, numerous medium to large eYFP-expressing neurons were evident at both dorsal and ventral levels of the DG (Fig. $2 A, D, G, J$ ). To confirm the putative glutamatergic phenotype of these neurons, the sections were processed for GluA2 immunohistochemistry. Virtually all eYFPlabeled neurons expressed GluA2 at all levels of the DG (Fig. 2B, $C, E, F)$, supporting the identity of the eYFP-labeled neurons as MCs throughout the DG.

In a similar set of sections processed for calretinin immunohistochemistry, eYFP-labeled neurons in the dorsal hilus were not labeled for calretinin, although a limited number of small neurons, presumed to be GABAergic interneurons or immature granule cells (Liu et al., 1996; Brandt et al., 2003), expressed calretinin (Fig. $2 H, I$ ). In contrast, in the ventral hilus, virtually all eYFP-labeled neurons were labeled for calretinin (Fig. $2 K, L$ ). Previous studies have also described calretinin-labeled neurons throughout the ventral levels of the DG (Liu et al., 1996; BlascoIbáñez and Freund, 1997). 

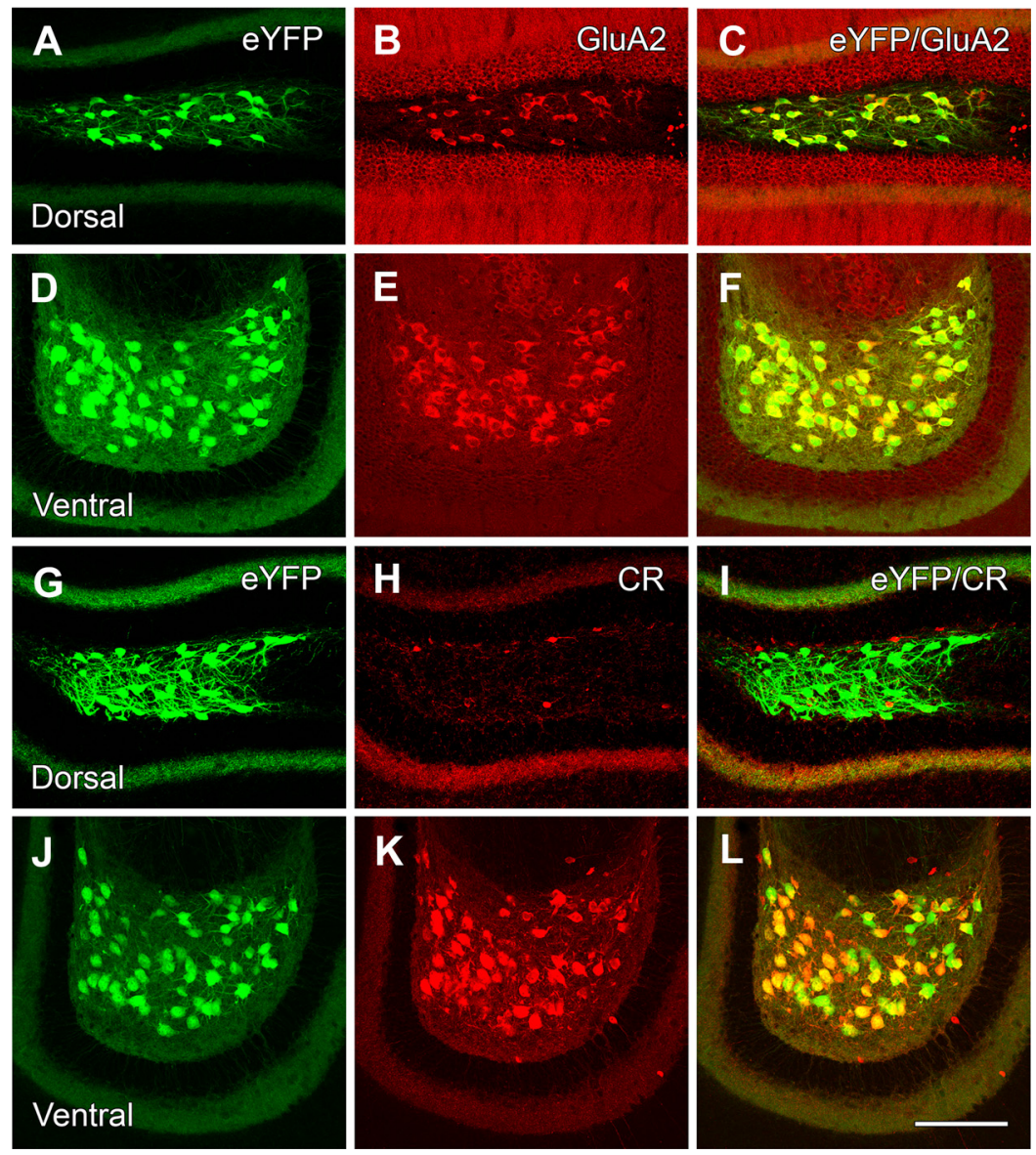

Figure 2. eYFP-labeled hilar neurons express GluA2 in both the dorsal and ventral DG but express calretinin (CR) in only the ventral region. $\boldsymbol{A}-\boldsymbol{F}$, Numerous hilar neurons in the dorsal and ventral DG express eYFP $(\boldsymbol{A}, \boldsymbol{D})$, are labeled for GluA2 $(\boldsymbol{B}, \boldsymbol{E})$, and are virtually all double labeled $(\boldsymbol{C}, \boldsymbol{F}) . \boldsymbol{G}-\boldsymbol{L}$, Presumed MCs in the dorsal and ventral hilus are labeled for eYFP $(\boldsymbol{G}, \boldsymbol{J})$ but lack $C R$ labeling in the dorsal hilus $(\boldsymbol{H}, \boldsymbol{I})$ where only a small number of interneurons or immature granule cells are labeled for $(R$. In contrast, essentially all eYFP-labeled neurons in the ventral hilus $(\boldsymbol{J})$ express $(R(\boldsymbol{K}, \boldsymbol{L})$. Scale bars: $100 \mu \mathrm{m}(\boldsymbol{A}-\boldsymbol{L})$
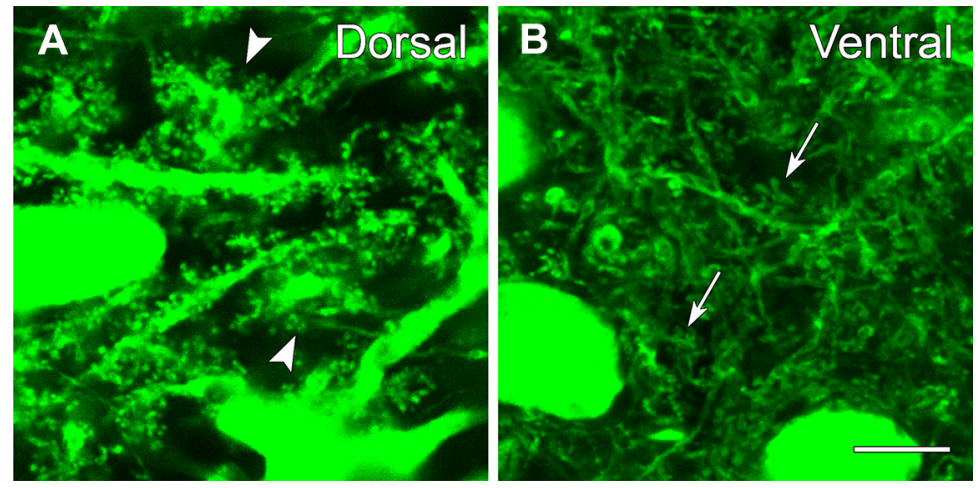

Figure 3. eYFP-labeled neurons exhibit numerous dendritic spines throughout the dentate hilus, but the spine morphology differs at dorsal and ventral levels. $\boldsymbol{A}$, In the dorsal hilus, numerous complex spines are evident along the dendrites, and many resemble the thorny excrescences (arrowheads) that characterize some MCs. $\boldsymbol{B}$, In the ventral hilus, labeled spines are abundant (arrows) but are generally less complex than those of labeled neurons in the dorsal hilus. Scale bars: $10 \mu \mathrm{m}(\boldsymbol{A}, \boldsymbol{B})$.

Further study of the morphology of the eYFP-labeled neurons revealed numerous dendritic spines on these neurons in both the dorsal and ventral hilus, consistent with their identification as MCs (Fig. 3A,B). At dorsal levels, many eYFP-labeled neurons displayed large spiny appendages along their proximal dendrites, and these closely resembled the thorny excrescences that are characteristic of some MCs (Amaral, 1978; Fig. 3A). In contrast, the spines of labeled neurons in the ventral hilus, although numerous, were smaller and less complex than those at dorsal levels (Fig. $3 B$ ). Thus, despite the lack of calretinin labeling, eYFP-labeled neurons in the dorsal hilus could be identified as MCs, based on their characteristic spines as well as their GluA2-positive phenotype. Similar differences in spine morphology in presumed MCs have been described in C57BL/6 mice following broad labeling of the hilar regions with Golgi impregnation and intracellular labeling methods (Fujise et al., 1998). The current findings confirm the differences with Cre-dependent expression of fluorescent markers.

Cre-dependent eYFP labeling in two transgenic mouse lines thus supports the identity of the labeled neurons as MCs in both the dorsal and ventral DG, based on their relatively large size, numerous dendritic spines and GluA2 (putative glutamatergic) phenotype, while also confirming differences between MCs in dorsal and ventral regions.

\section{Dorsal and ventral MCs were selectively labeled}

Transfections were targeted to either dorsal or ventral regions of the DG. Numerous cell bodies were labeled at the levels of the transfections, and diffusion of the viral vector extended for $\sim 500 \mu \mathrm{m}$ on either side of the injection sites. This led to cell body labeling throughout $\sim 40 \%$ of both the rostral and caudal DG. The middle $20 \%$ of the dentate had variable labeling. Often the labeling in this region was low, but in some animals the transfections overlapped to some extent. Nevertheless, distinct patterns of labeling from the dorsal and ventral transfections were consistently observed.

\section{Dorsal MCs have unique patterns of axonal projections}

We initially studied the axonal projections of the two groups of MCs separately, with unilateral transfections in either the dorsal or ventral hilus. Our studies focused first on the axonal patterns of MCs in the dorsal DG, including their commissural projections. Following unilateral transfections and eYFP labeling of cell bodies in the dorsal hilus, commissural projections were evident in the contralateral DG (Fig. 4A). When studied in detail, this projection consisted of a relatively narrow dense band of fibers in the inner molecular layer, concentrated at a slight distance from the outer border of the granule cell layer (Fig. 4B). A more diffuse plexus of fibers 
extended further into the molecular layer (Fig. 4B). A plexus of fine fibers also filled the contralateral hilus (Fig. 4B).

On the ipsilateral (transfected) side, strong labeling of cell bodies and their processes extended throughout the hilus, delineating this region (Fig. 4A,C). Labeled fibers were also present in the inner molecular layer on the ipsilateral side (Fig. 4C), but these fibers were much less numerous than those on the contralateral side (Fig. 4, compare $B, C$ ).

Labeled fibers on the ipsilateral side continued caudally as associational fibers (Fig. $5 A-C$ ) (Figs. 4 and 5 show the progression of labeling from rostral to caudal in the same animal). These ipsilateral projections were sparse at the level of the labeled cell bodies (Fig. 5A) but increased at more caudal levels (Fig. 5B,C). The distribution of the labeled fibers also changed substantially. As the associational projections extended to caudal levels, they expanded beyond the inner third of the molecular layer and became more diffuse. At anterior levels of the ventral dentate, beyond the level of the labeled cell bodies, these associational projections extended into the middle of the molecular layer (Fig. 5B). Further ventrally, these projections formed a narrower band within the middle molecular layer (Fig. 5C).

On the contralateral side, the commissural fibers formed a distinct band of labeled fibers in the inner molecular layer at all levels in which labeled cell bodies were evident on the transfected side (Fig. 5A). However, some diffuse labeling was also evident in the molecular layer (Fig. 5A). As the commissural fibers reached ventral levels, they assumed patterns that were very similar to those of the ipsilateral associational fibers, becoming wider and more diffuse and then forming a narrower band at more ventral levels (Fig. 5B,C). Although the patterns of labeling were very similar on the two sides at ventral levels, the projections on the ipsilateral side (associational projections) were frequently stronger than those on the contralateral side (commissural projections).

With the dorsal injections used in this study, MC somata were extensively labeled in the rostral $40 \%$ of the DG, extending from the most rostral end of the dentate hilus through $\sim 1500-$ $1800 \mu \mathrm{m}$ of the DG. (This length includes substantial shrinkage of the tissue as a result of the histologic processing.) Because of the relatively large longitudinal extent of cell body labeling, the length of the axonal projections from MCs at any single level could not be determined. However, with the current transfections, labeled fibers extended through $\sim 80 \%$ of the DG on the ipsilateral side and slightly less on the contralateral side. While the longitudinal projections from the dorsal MCs were extensive, they often did not reach the most ventral DG.

In summary, dorsal MCs formed a strong commissural pathway at the level of the cell bodies of origin (Fig. 5A). At more caudal (ventral) levels, both the ipsilateral (associational) and contralateral (commissural) projections become more diffuse, expanding into the middle of the molecular layer at anterior ventral levels, and then forming narrower bands of fibers in the middle molecular layer at more ventral levels (Fig. 5B,C). These patterns of labeled fibers from dorsal MCs differ substantially from the dense band of fibers in the inner one-third to onefourth of the molecular layer that is classically associated with the axonal projections of MCs.

\section{Ventral MCs exhibit characteristic patterns of axonal projections}

To characterize the projections of the ventral MCs with the same methods, a viral vector for Cre-dependent eYFP was transfected unilaterally at caudal levels of the DG, labeling numerous MCs in ventral regions of the DG. On the ipsilateral side, a band of labeled fibers was evident in the inner molecular layer at the level of the transfection, but the fibers were sparse, particularly at the most caudal levels (data not shown). A similar band of fibers 

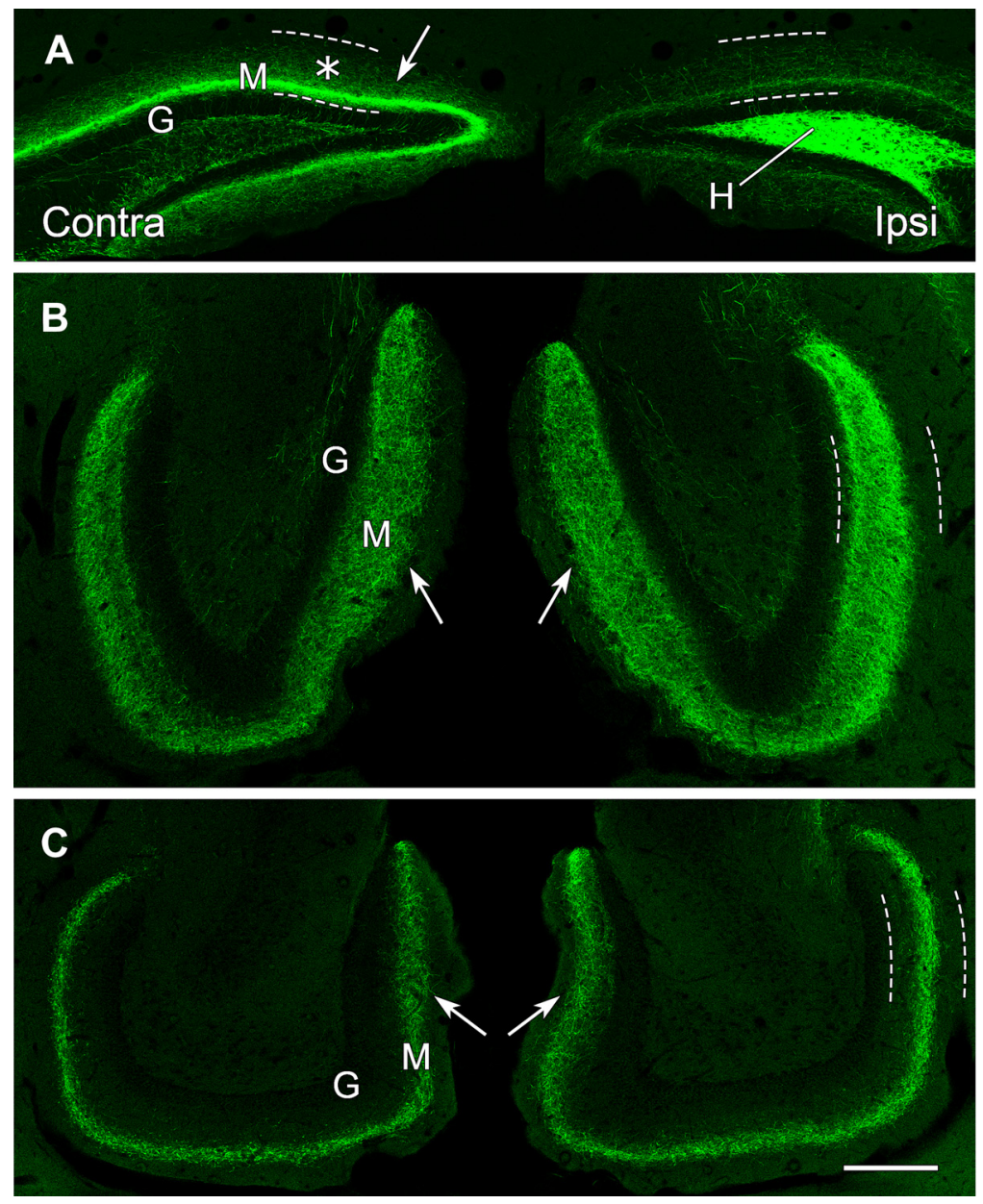

Figure 5. eYFP-labeled MCs in the hilus of the dorsal DG provide strong commissural projections to the contralateral dentate, but the projections shift positions and become more diffusely organized as they extend ventrally as commissural and associational fibers. $A$, In a coronal section at $600 \mu \mathrm{m}$ further caudal than the section in Figure 4, commissural projections from dorsal MCs in the hilus $(\mathrm{H})$ remain stronger on the contralateral side (arrow), near the unlabeled granule cell layer $(\mathrm{G})$, than on the transfected side, and increased diffuse labeling $(*)$ is evident in the molecular layer (M). Dashed lines delineate the borders of the molecular layer in all panels. $\boldsymbol{B}$, In a horizontal section at an anterior ventral level, beyond the level of labeled cell bodies, the axonal projections (arrows) expand and become more diffuse bilaterally. $C$, In a horizontal section at a more ventral level, the MC projections (arrows) form a narrower but distinct band in the molecular layer on each side. Scale bars: $200 \mu \mathrm{m}(\boldsymbol{A}-\boldsymbol{C})$.

could be detected on the contralateral side, but this commissural projection was generally weak and thus differed from the strong commissural projection of the dorsal MCs. As the axonal projections extended rostrally, the bands of labeled fibers became stronger and were prominent bilaterally. The labeled fibers remained within the inner molecular layer throughout the ventral to dorsal extent of the DG and thus replicated the classical pattern of MC axons. These same patterns were observed in animals with double labeling in which eYFP was expressed in ventral MCs and mCherry was expressed in dorsal MCs (Fig. $6 A-D)$. The transfections were made unilaterally at the same locations as those used for single labeling.

The ventral transfections labeled cell bodies in the caudal $40 \%$ of the DG. This included the majority of MCs in the wider, more expansive ventral regions of the dentate hilus, when analyzed in horizontal sections (Fig. 6D). Labeled cell bodies were also abundant at more anterior levels of the ventral dentate where the hilus assumes an elongated shape in horizontal sections (Fig. 6C). With the extent of cell body labeling obtained following the ventral transfections, labeled axonal projections extended rostrally throughout the remainder of the DG, including the most rostral regions of the DG. The labeled fibers were concentrated in the inner $20-25 \%$ of the molecular layer and remained in this location at all rostral-caudal levels (Fig. 6A-D).

\section{Dorsal and ventral MCs have distinct patterns of axonal projections}

The projections of dorsal and ventral MCs were then compared in the same sections. At rostral (dorsal) levels, the projections from the two groups of neurons overlapped to a considerable extent, with labeling localized primarily in the inner molecular layer (Fig. 6A,B). At rostral levels, projections from dorsal MCs appeared strongest on the contralateral side, consistent with a strong commissural pathway (Fig. 6A). At these same levels, the ipsilateral projections from ventral MCs predominated and occluded the weaker ipsilateral innervation from dorsal MCs (Fig. 6A,B). At ventral levels, the axonal projections from dorsal MCs diverged and occupied the middle region of the molecular layer (Fig. 6C,D). In contrast, axonal projections of the ventral MCs remained within the inner molecular layer throughout the longitudinal extent of the DG (Fig. 6A-D). Thus, at ventral levels, the axonal projections from dorsal and ventral MCs occupied separate regions of the molecular layer (Fig. 6C,D).

Measurements of the widths of the projections from dorsal and ventral MCs demonstrated that projections from ventral MCs occupied relatively similar extents of the molecular layer throughout the DG, occupying an average of $22.4 \%$ (range: $18.7-27.3 \%$ ) of the molecular layer (Table 1). In contrast, the width of the dorsal to ventral projections varied substantially along the longitudinal axis, occupying $33.4 \%$ and $34.6 \%$ of the inner molecular layer at dorsal levels (contralateral side); expanding to $54.9 \%$ of the molecular layer at anterior ventral levels; and then becoming narrower and occupying $24.2 \%$ of the molecular layer at posterior ventral levels (Table 1).

To verify that the labeling patterns were not because of the varying planes of section through the DG, the hippocampus was sectioned transversely, perpendicular to the long axis of the hippocampus, in animals with unilateral transfections of mCherry rostrally and eYFP caudally. The transverse sections demonstrated selective labeling of the cell bodies of MCs in the rostral DG with mCherry (Fig. $7 A-D$ ), and selective labeling of the cell bodies of MCs in the more caudal dentate with eYFP (Fig. $7 E-$ $H$ ). This labeling resulted in a band of eYFP-labeled fibers in the inner molecular layer throughout the DG, with increasingly strong labeling of this band at rostral levels (Fig. $7 A-D$ ). At these levels, labeled axons of the ventral MCs occluded the less dense ipsilateral projections from dorsal MCs (Fig. $7 A-D$ ). At more caudal levels, the projections from mCherry-labeled MCs of the rostral dentate extended into the middle region of the molecular layer (Fig. $7 D-G$ ), and both projections could be visualized because of the lack of overlap in their distributions at caudal levels. These results confirmed the different patterns of longitudinal 
projections from dorsal and ventral MCs in the same section and demonstrated that the observed patterns were not related to different planes of section through the DG.

To further clarify the laminar location of the dorsal and ventral MC projections in relation to the granule cells, the nuclei of granule cells were labeled with DAPI. Axonal projections of the ventral MCs formed a dense band adjacent to the granule cell layer at both ventral and dorsal levels of the DG, with the strongest labeling in the dorsal dentate, at a considerable distance from the labeled MCs (Fig. 8A,B). In contrast, axons of the dorsal MCs projected to the middle of the molecular layer at ventral levels. (Fig. 8B). Thus, the axonal projections from dorsal and ventral MCs, while overlapping at rostral levels (Fig. $8 A$ ), were clearly separated and formed distinct laminar patterns at ventral levels of the DG (Fig. 8B,C). Projections from ventral MCs occupied the inner molecular layer, adjacent to the granule cell layer (Fig. 8C) and were thus located in the classical commissural/associational zone, the expected location of MC fibers. In contrast, the projections from dorsal MCs formed a second, more diffuse layer of fibers that occupied the middle molecular layer, where they could overlap with fibers of the medial perforant path (Fig. 8C). While it has not been possible to demonstrate the overlap of these pathways directly, the band of MC fibers in the middle molecular layer at caudal levels is remarkably similar to that of the medial perforant path fibers, identified by anterograde labeling, in the mouse (Deller et al., 1999; van Groen et al., 2003; Woods et al., 2018) and rat (Witter, 2007).

In addition to different locations of dorsal and ventral MC projections in the molecular layer, the patterns of the fibers were distinctly different. Ventral MCs formed a more concentrated band of fibers close to the outer border of the granule cell layer. In contrast, fibers from dorsal MCs were distributed more diffusely, particularly at caudal levels of the DG (Fig. 8C). Thus, both the locations and the organizational patterns of the dorsal and ventral MCs differed, suggesting possibly different functional roles.

\section{Both dorsal and ventral MCs have extensive projections}

The present findings are consistent with previous descriptions of axonal projections from the hilar region but provide greater specificity as MCs are selectively labeled. By labeling MCs unilaterally in each region and studying their projections bilaterally, three major axonal projections were identified from each group of MCs, a direct commissural projection at the level of the cell bodies of origin; an ipsilateral associational pathway; and a longitudinal commissural pathway that extends through
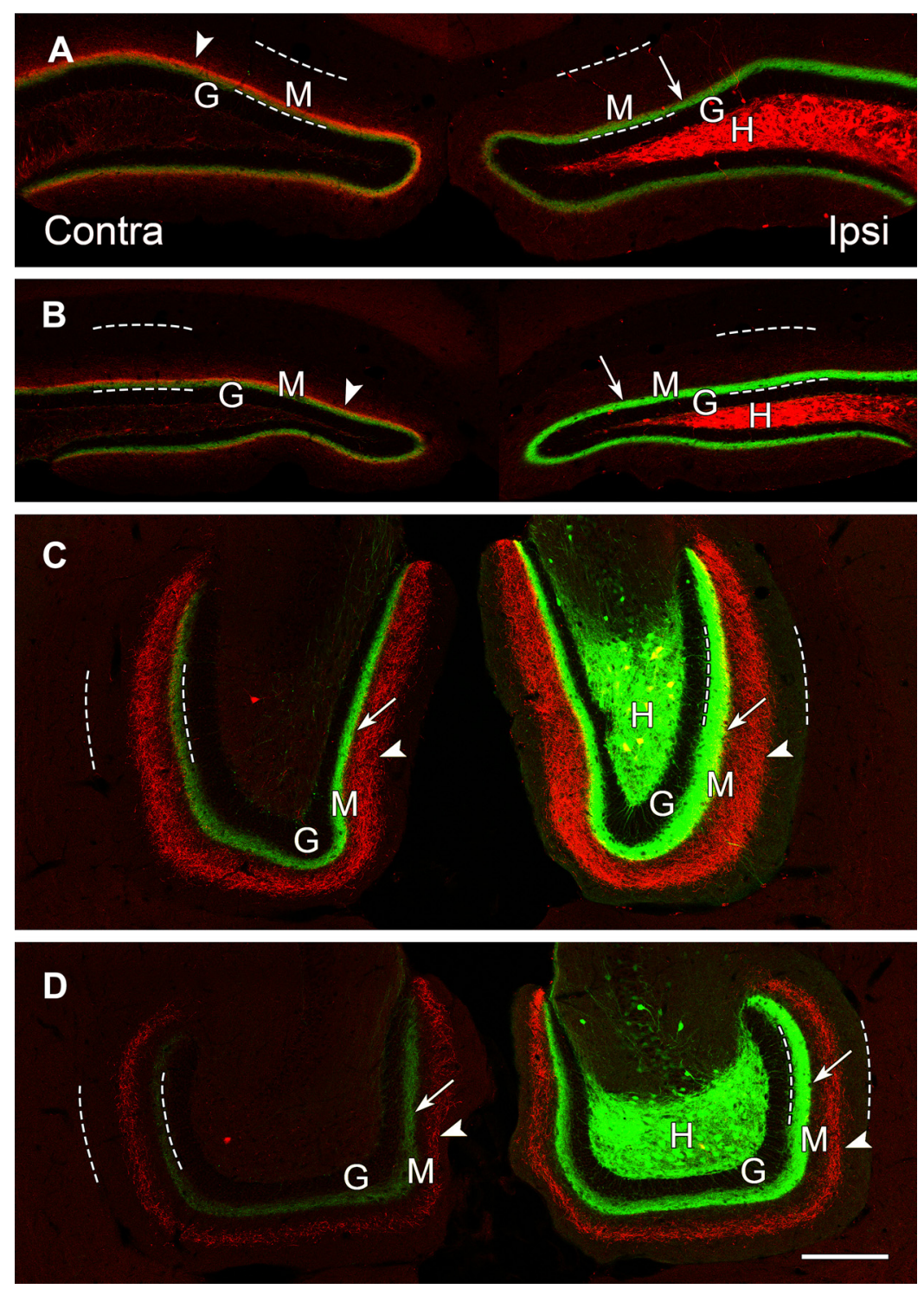

Figure 6. The patterns of axonal projections of dorsal (mCherry-labeled) and ventral (eYFP-labeled) MCs differ as the fibers extend through the DG. $\boldsymbol{A}, \boldsymbol{B}$, In dorsal, coronal sections, projections from the dorsal and ventral MCs largely overlap in all panels. C, D, At ventral levels, the projections from dorsal and ventral MCs diverge and no longer overlap. A dense projection from the ventral MCs (eYFP) is present bilaterally (arrows), adjacent to the unlabeled granule cell layer (G), while a more diffuse fibers (arrowheads) from the dorsal MCs is evident in the middle molecular layer. Both projections are strongest on the ipsilateral side. At anterior ventral levels $(\boldsymbol{C})$ a few double-labeled cell bodies (yellow) are evident in the hilus, suggesting some overlap of the dorsal and ventral transfections at this level. Scale bars: $200 \mu \mathrm{m}(\boldsymbol{A}-\boldsymbol{D})$.

the contralateral DG in parallel with the ipsilateral associational fibers. The bilateral symmetry of the longitudinal associational and commissural pathways was striking (Figs. 5B,C, 6C,D) and has been noted with interest in previous studies in which both pathways were studied (Fricke and Cowan, 1978; Swanson et al., 1978; Deller et al., 1995). The present findings also confirm previous descriptions of limited labeling of the associational fibers at the level of the cell bodies of origin but substantially stronger labeling at distant sites (Amaral and Witter, 1989; Buckmaster et al., 1996). This pattern was observed for both groups of MCs (Fig. 8A,B).

Advantages and limitations of the neuroanatomical methods With the current methods, it has been possible to selectively transfect either dorsal or ventral MCs unilaterally, and this has 
Table 1. Comparison of widths of labeled projections in molecular layer from dorsal and ventral MCs at dorsal (coronal) and ventral (horizontal) levels

\begin{tabular}{|c|c|c|c|c|c|}
\hline \multirow[b]{2}{*}{ Level of section } & \multirow[b]{2}{*}{$\begin{array}{l}\text { Width of molecular layer } \\
(\mu \mathrm{m} \pm \mathrm{SD})\end{array}$} & \multicolumn{2}{|c|}{ Dorsal to ventral projections } & \multicolumn{2}{|c|}{ Ventral to dorsal projections } \\
\hline & & $\begin{array}{l}\text { Width } \\
(\mu \mathrm{m} \pm \mathrm{SD})\end{array}$ & $\begin{array}{l}\% \text { of molecular } \\
\text { layer width }\end{array}$ & $\begin{array}{l}\text { Width } \\
(\mu \mathrm{m} \pm \mathrm{SD})\end{array}$ & $\begin{array}{l}\% \text { of molecular } \\
\text { layer width }\end{array}$ \\
\hline Dorsal, anterior ipsilateral & $166.0 \pm 14.3$ & $20.2 \pm 3.2$ & $12.1 \%$ & $37.4 \pm 6.6$ & $22.5 \%$ \\
\hline Dorsal, anterior contralateral & $164.8 \pm 19.9$ & $57.1 \pm 2.6$ & $34.6 \%$ & $33.6 \pm 5.3$ & $20.3 \%$ \\
\hline Dorsal, posterior ipsilateral & $162.4 \pm 25.2$ & $19.9 \pm 3.6$ & $12.2 \%$ & $34.4 \pm 9.9$ & $21.1 \%$ \\
\hline Dorsal, posterior contralateral & $154.9 \pm 16.3$ & $51.8 \pm 10.6$ & $33.4 \%$ & $29.0 \pm 6.0$ & $18.7 \%$ \\
\hline Ventral, anterior ipsilateral & $240.8 \pm 40.9$ & $132.3 \pm 26.2$ & $54.9 \%$ & $58.4 \pm 9.7$ & $24.2 \%$ \\
\hline Ventral, posterior ipsilateral & $200.4 \pm 33.9$ & $48.5 \pm 10.9$ & $24.2 \%$ & $54.8 \pm 9.8$ & $27.3 \%$ \\
\hline
\end{tabular}

Measurements from suprapyramidal blade of the $\mathrm{DG} ; n=12$ (mean of three measurements/level $\times$ four animals).
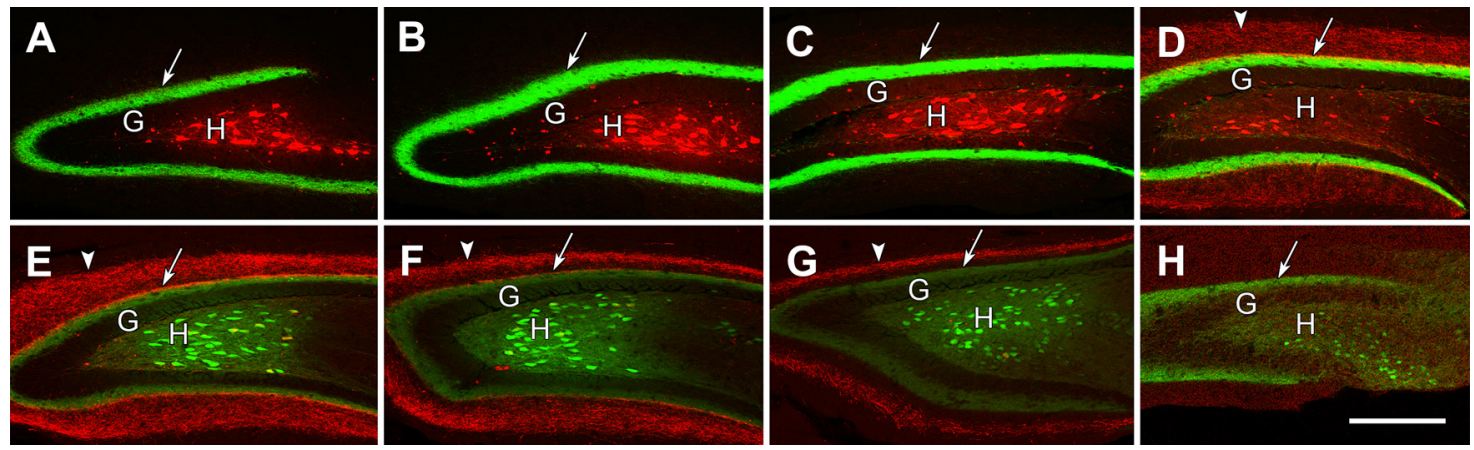

Figure 7. Labeling of dorsal MCs with mCherry and ventral MCs with eYFP demonstrate the progressive changes in their axonal projections throughout the DG in a series of transverse sections through an elongated hippocampus at $600-\mu \mathrm{m}$ intervals. $\boldsymbol{A}-\boldsymbol{H}$, At rostral levels $(\boldsymbol{A}-\boldsymbol{D})$, mCherry-labeled MCs are abundant in the dentate hilus (H), deep to the granule cell layer (G). At more caudal levels $(\boldsymbol{E}-\boldsymbol{H})$, eYFP-labeled MCs predominate, and there is little overlap of the two labels in this animal. The dense axonal projections from caudal MCs (arrows) are strong and predominate at rostral levels $(\boldsymbol{A}-\boldsymbol{D})$, but are weaker at the level of their labeled cell bodies $(\boldsymbol{E}-\boldsymbol{H})$. The axonal projections from rostral MCs are occluded at rostral levels $(\boldsymbol{A}-\boldsymbol{C})$ where the ipsilateral projections of these neurons are weak, but the projections expand into the molecular layer at more caudal levels $(\boldsymbol{D}-\boldsymbol{H})$, forming a wider diffuse band (arrowheads) at anterior ventral levels $(\boldsymbol{D}, \boldsymbol{E})$ and a narrower band (arrowheads) at more caudal levels $(\boldsymbol{F}, \boldsymbol{G})$. At ventral levels, the innervation from rostral and caudal MCs form non-overlapping laminar distributions in the molecular layer $(\boldsymbol{D}-\boldsymbol{H})$. Scale bars: $200 \mu \mathrm{m}(\boldsymbol{A}-\boldsymbol{H})$.

been critical for identifying differences in their projections. With more extensive labeling throughout the dentate or at intermediate levels, the distinction between the projections could have been obscured, due either to overlap of the pathways or limitations of the imaging methods in which strong labeling of fibers from ventral MCs could limit visualization of the more diffuse projections from dorsal MCs.

There are also limitations of the methods. With the current methods and experimental design, it was not possible to trace the projections of single or small groups of MCs. Thus, although the projections of MCs in the dorsal and ventral regions are currently described as unidirectional, the individual MCs are likely to extend their axons in both directions, as described in previous studies of intracellularly-labeled MCs (Buckmaster et al., 1996). In the current study, the axons of labeled MCs could be projecting in both directions, but only the projections from the most distal groups of labeled neurons (those projecting away from the labeled MCs) could be detected. Projections in the other direction would be occluded by the extensive labeling of additional MCs in these regions. However, even when bidirectional, the projections could extend further in one direction than the other. Our findings support a preferential direction for the axonal projections of populations of dorsal and ventral MCs, depending on the location of the cell bodies along the longitudinal extent of the DG. Preferential directions of the projections were also suggested in an early autoradiographic study of associational and commissural projections in the rat (Fricke and Cowan, 1978). Likewise, the axons of some intracellularly labeled MCs extended further in one direction than the other (Buckmaster et al., 1996). It is also possible that some MCs, particularly those near the middle of the DG, could extend their projections relatively equally in both directions. More limited transfections would be required to distinguish projections from MCs in finer subdivisions of the DG.

Dorsal MCs excite ventral DG granule cells

Mice with dorsal MCs transfected by ChR2-eYFP were used to explore the function of the projections of these cells to the ventral DG. Single pulse light stimulation of dorsal MC projections in ventral slices evoked EPSCs in both ipsilateral and contralateral ventral dentate granule cells (Fig. 9A). All 14 recorded ipsilateral granule cells responded to the light stimulation. The average values of the EPSC properties were as follows: amplitude $27.56 \pm 8.17 \mathrm{pA}, 10-90 \%$ rising rate $13.37 \pm 3.76 \mathrm{pA} / \mathrm{ms}$, decay time constant $8.09 \pm 1.36 \mathrm{~ms}$ and latency (from the onset of the light pulse) $5.36 \pm 0.54 \mathrm{~ms}$. Only four out of 15 recorded granule cells on the contralateral side showed light evoked EPSCs. This is a significantly lower ratio of excited granule cells than that found on the ipsilateral side $(p<0.0001$, two-tailed Fischer's exact test). The average values for contralateral EPSC parameters were: amplitude $11.21 \pm 2.09 \mathrm{pA}, 10-90 \%$ rising rate $3.33 \pm 0.81 \mathrm{pA} / \mathrm{ms}$, decay time constant $6.53 \pm 1.00 \mathrm{~ms}$ and latency $5.03 \pm 0.88 \mathrm{~ms}$. There were no significant differences comparing these parameters between ipsilateral and contralateral recordings (Mann-Whitney test, $p=0.297$ for amplitudes, $p=0.116$ for rising rates, $p=0.894$ for decay time constants, and $p=0.816$ for latencies). We also performed optical train stimulations on the ChR2 transfected MC projections. The optically evoked EPSCs in granule cells could only follow a 20$\mathrm{Hz}$ frequency of stimulation in ipsilateral slices (Fig. 9B) with 
an averaged paired ratio (amplitude of second evoked EPSC/first evoked EPSC for every train) of $1.41 \pm 0.26(n=5)$. The paired-pulse facilitation ratio at $50 \mathrm{~ms}$ inter-stimulus interval implies that these MC axons have a low release probability. The ChR2-expressing fibers could not adequately follow $40-\mathrm{Hz}$ stimulation on either side (data not shown), consistent with previous reports (Hashimotodani et al., 2017).

In slices from mice with unilateral ChR2eYFP-expressing MCs in the dorsal DG, the light pulse evoked IPSCs could be recorded in 9/14 ipsilateral granule cells in the ventral DG. This is significantly less than the number of cells (14/14) in which EPSCs could be evoked ( $p=0.0169$, twotailed Fischer's exact test), indicating that the dorsal MC projection is mainly excitatory onto the ventral granule cells. No light evoked IPSCs could be recorded in 15 granule cells on the contralateral side which is significantly different from the results on the ipsilateral side $(p<0.0002$, twotailed Fischer's exact test).

\section{Projections from dorsal MCs facilitate granule cell responses to perforant path stimulation in the ventral DG}

To further explore the function of the diffuse projection from dorsal MCs onto the ventral granule cells and its interaction with other pathways, we examined the interaction between the perforant path and the MC input onto granule cells. In 4 mice we performed an electrical stimulation of the perforant path fibers outside the hippocampal fissure together with local optical stimulation of the dorsal MC projections in the ventral dentate molecular layer. The EPSPs of dentate granule cells in horizontal slices were monitored using whole-cell patch clamp recordings under current clamp. Once granule cells without optically induced responses were rejected from further recordings, we adjusted the current intensity of the perforant path electrical stimulation to evoke subthreshold EPSPs in each recorded granule cell.

The single pulse optical stimulation of the dorsal MC axons evoked an EPSP in granule cells $(1.44 \pm 0.19 \mathrm{mV}, n=19)$, while the electrical stimulation of the medial perforant path generated EPSPs of $3.70 \pm 0.33 \mathrm{mV}(n=19)$. To examine possible interactions between the two pathways, we first stimulated the MC projections 50 or $25 \mathrm{~ms}$ before stimulating the perforant path. The EPSPs evoked by perforant path stimulation preceded by an optical stimulation at $25 \mathrm{~ms}$ were similar to those evoked by perforant path stimulation alone (average perforant path evoked EPSPs: $3.98 \pm 0.51 \mathrm{mV}, n=7)$. When the optical stimulation preceded the perforant path stimulation by $50 \mathrm{~ms}$, the average perforant path evoked EPSPs was $3.27 \pm 0.31 \mathrm{mV} \quad(n=7)$, not significantly different from the 25 -ms interval ( $p=0.6873$, nonparametric Kruskal-Wallis test). Next, we stimulated the MC projections and perforant path simultaneously, and obtained EPSPs of $6.12 \pm 0.32 \mathrm{mV}$ in amplitude $(n=19)$. We also calculated the arithmetic sum of the two differentially evoked EPSPs in the same recorded granule cells obtaining an average value of $4.96 \pm 0.41 \mathrm{mV}(n=19)$ in amplitude. An example of the evoked EPSP traces and their corresponding arithmetic summed trace is shown in Figure 9C. The amplitudes of EPSPs evoked by simultaneously stimulating the MC projections and perforant path were significantly larger than the arithmetic sum of the individually evoked EPSPs $(p<0.0001$, Wilcoxon matched-pairs signedrank test, $n=19$; Fig. $9 D$ ). Thus, dorsal MC projections facilitate the excitation of granule cells by the perforant path in the ventral DG when the two inputs occur simultaneously, but not when they are desynchronized by at least $25 \mathrm{~ms}$.

\section{Discussion}

The major finding of this study is that MCs in the dorsal and ventral DG have different patterns of axonal projections in the molecular layer. Axons of ventral MCs form a dense band of fibers within the inner molecular layer throughout their caudal to rostral extent, consistent with the classical description of $\mathrm{MC}$ fibers. In contrast, projections of dorsal MCs have a more diffuse distribution that expands beyond the inner molecular layer as the axons reach caudal levels. The different distributions of axonal projections suggest that dorsal and ventral MCs could have different functional roles.

\section{Dorsal and ventral subgroups of MCs}

The distinct patterns of axonal projections from dorsal and ventral MCs provide new evidence for different subgroups of MCs. Previous studies have demonstrated differences between these groups of MCs in their expression of calretinin and spine morphology (Liu et al., 1996; Blasco-Ibáñez and Freund, 1997; Fujise et al., 1998), as confirmed in the present studies, as well as differences in their electrophysiological properties (Jinno et al., 2003), activity during behavioral tasks (Duffy et al., 2013; Moretto et al., 2017), and patterns of gene expression (Bienkowski et al., 2018). 

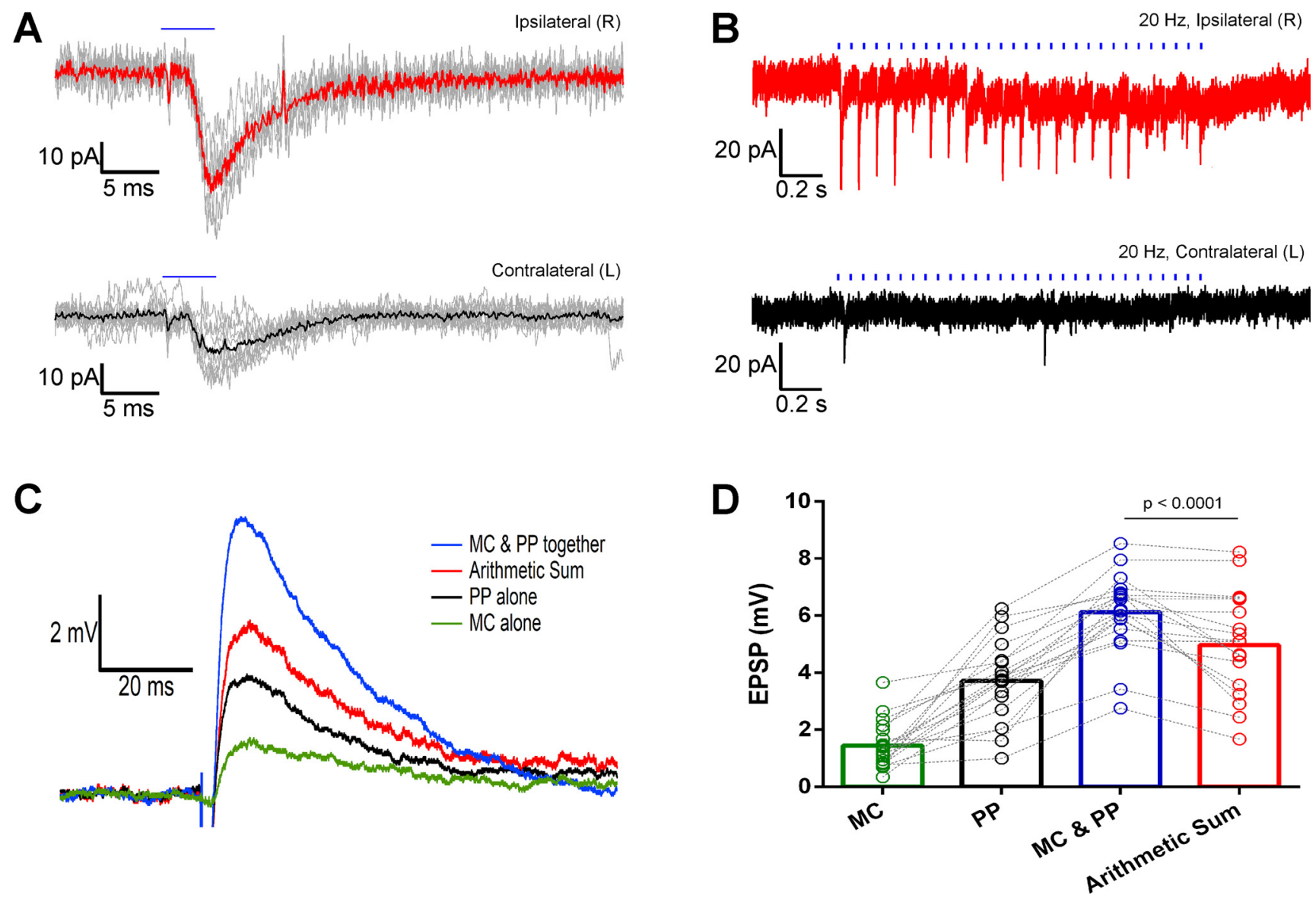

Figure 9. Optically evoked EPSCs and EPSPs in ventral DG granule cells through stimulation of dorsal MC projections in the DG molecular layer. $\boldsymbol{A}$, Single light pulse stimulation (5 ms) evoked EPSCs (gray) and their averages (thick red or black lines) in granule cells from mice with ChR2-eYFP unilaterally transfected dorsal MCs. $\boldsymbol{B}$, EPSCs evoked in ventral granule cells by a 20-Hz train optical stimulation of the ChR2-eYFP-expressing dorsal MC axons. Recordings from ipsilateral (red) and contralateral (black) granule cells. Blue horizontal bars indicate the duration of the optical stimulation. C, EPSPs evoked by optical stimulation of the MC projections (MC) in the dentate molecular layer (green), electrical stimulation of the medial perforant path (PP) outside the hippocampal fissure (black), and simultaneous stimulation of the two pathways (MC and PP; blue). The red trace is the digital arithmetic sum of the green trace (evoked by MC) and black trace (evoked by PP). D, Bar graph showing the summary and statistics of all the evoked EPSPs and the arithmetic sum traces. The MC and PP evoked EPSPs are significantly larger than those evoked by PP stimulation only $(p<0.0001$, paired Wilcoxon test).

Despite evidence that MCs are not a homogeneous population, it has generally been assumed that all MCs have the same termination patterns in the molecular layer. Thus, it was surprising to find that dorsal and ventral MCs have different axonal distributions. The projection from dorsal MCs is unique and has not been described previously. However, an earlier tracing study in the rat described presumed MC fibers near the middle of the molecular layer (Deller et al., 1995), and this is similar to the location of dorsal MC fibers in the current study.

\section{Functions of dorsal and ventral MC projections}

Determining the functions of axonal projections from both dorsal and ventral MCs presents a new challenge. Recent in vivo studies of dorsal MCs have focused on the activity at the level of their cell bodies and demonstrated that these cells are highly active, have multiple place fields, and show more robust remapping of place fields than granule cells (Danielson et al., 2017; GoodSmith et al., 2017; Senzai and Buzsáki, 2017). The effects of these MCs on neurons at distant sites in vivo remains largely unknown but will be exerted through their commissural and associational projections.

Current findings demonstrated a prominent commissural projection from dorsal MCs, and this projection has received the most attention in physiological studies. While this commissural projection can exert both excitatory and inhibitory effects on granule cells (Scharfman, 1995; Chancey et al., 2014; Hsu et al., 2016; Yeh et al., 2018), in vitro studies have generally suggested that this projection has net inhibitory effects on granule cells (Buzsàki and Eidelberg, 1981; Douglas et al., 1983; Jinde et al., 2012). However, optogenetic studies have recently demonstrated that repetitive stimulation of the commissural fibers at physiologically relevant frequencies can enhance excitation of the granule cells and induce presynaptic long-term potentiation (LTP; Hashimotodani et al., 2017). Thus, there is a mechanism for strengthening the excitatory effects on granule cells under certain conditions. These findings are consistent with morphologic evidence for an abundance of excitatory synapses on the proximal dendrites of granule cells (Buckmaster et al., 1996; Wenzel et al., 1997; Sloviter et al., 2003).

Dorsal MCs also form a unique associational projection that extends caudally through the DG and at ventral levels is located in the middle molecular layer, the location of the medial perforant path. As the physiological effects of these associational fibers have not been described, we studied the effects of optical stimulation of these fibers in horizontal slices in which only labeled fibers were present and found predominantly excitatory effects in granule cells of the ventral dentate. The unexpected location of these MC projections in the middle molecular layer led us to 
investigate potential interactions between dorsal MC projections and the perforant path. We found that simultaneous optical activation of dorsal MC projections and electrical stimulation of the perforant path produced a supralinear response, suggesting that dorsal MCs can enhance the effects of the perforant path in the ventral DG.

In a previous study of the associational pathway of the DG in anesthetized rats, responses were elicited by direct stimulation of the hilus, presumably activating longitudinally projecting MCs (Hetherington et al., 1994). Such stimulation also had a net excitatory effect on dentate granule cells, and tetanic stimulation led to LTP of the pathway. Interestingly, LTP was produced reliably only when this pathway was stimulated in the dorsal to ventral direction, thus corresponding to the direction of the stimulated fibers in the current study.

Our electrophysiological studies were focused on the dorsal to ventral MC projections because of their novelty and their putative overlap with fibers of the perforant path. Such overlapping patterns were not observed for the ventral to dorsal MC and perforant path fibers, but functional interactions are possible and remain to be explored in future studies.

Until recently, ventral MCs have received little direct study. However, our current findings suggest that ventral MCs form the "classical" MC pathway, and thus the in vivo functions of these MCs are of particular interest. In vivo studies have demonstrated that photo-stimulation of MCs in the ventral dentate can elicit responses in both granule cells and interneurons in the dorsal DG, thus confirming that ventral MCs can influence network activity of the DG at rostral levels (Bui et al., 2018). To determine the in vivo function of the ventral to dorsal MC pathway, Fredes et al. (2020) selectively targeted calretinin-positive (ventral) MCs in Calb2-Cre mice. They found that ventral MCs readily detected environmental novelty and relayed this information to dorsal granule cells. Interestingly, the ventral to dorsal MC projections were critical for novelty-induced contextual memory formation. The findings provide further evidence for unique functions of ventral and dorsal MCs and emphasize the importance of the longitudinal connections of MCs.

\section{Extensive longitudinal projections of MCs and their roles}

Current findings demonstrate that both dorsal and ventral MCs have extensive longitudinal projections, consistent with previous descriptions of associational fibers of MCs extending through as much as $60-70 \%$ of the DG (Amaral and Witter, 1989; Buckmaster et al., 1996). Functionally, these longitudinal projections are likely to be one of the most important features of MCs and could be critical for linking functions of ventral regions of the hippocampus mediating emotion and anxiety to those of dorsal regions associated with spatial memory and cognition (Fanselow and Dong, 2010; Kheirbek et al., 2013; Strange et al., 2014; Weeden et al., 2015). The importance of the longitudinal connections is supported by recent studies showing that silencing activity in either dorsal or ventral MCs during the learning phase of an object location memory test led to severe deficits (Bui et al., 2018), and exciting ventral MCs enhanced contextual memory in a familiar environment (Fredes et al., 2020), consistent with their role in some memory functions.

Viewed more broadly, the functional role of MCs will depend to a large extent on the net effects of the longitudinal projections. One major hypothesis suggests that the MC projections form a "granule cell association" network through which spatially dispersed granule cells could be co-activated and form functional ensembles that could contribute to memory (Buckmaster and Schwartzkroin, 1994). An alternate view is that the longitudinal connections constitute a broad inhibitory system that limits granule cell activity throughout much of the DG to allow selective granule cell activity (Zappone and Sloviter, 2004; Jinde et al., 2012; Sloviter and Lømo, 2012).

The current findings add another dimension to this discussion. It is possible that the functions of dorsal and ventral MCs differ, with direct excitatory effects predominating in some pathways, such as the dorsal to ventral associational projections, and disynaptic inhibitory effects predominating in others. In addition, the different innervation patterns of the dorsal and ventral MCs could be associated with different functional roles. The more highly concentrated projections from ventral MCs suggest a more targeted system with potentially stronger control at postsynaptic sites, because of the proximal locations of their synapses on dendrites in the molecular layer. In contrast, the more diffuse projections of dorsal MCs would be consistent with a modulatory role, as suggested by their enhancement of perforant path input in the current study. In this mode, dorsal MCs could exert their effects primarily through interactions with other inputs to dentate granule cells, and such synergistic interactions between the associational pathway and the perforant path have been suggested previously (Kleschevnikov and Routtenberg, 2003).

Beyond the normal functional roles of MCs, the extensive axonal projections of these neurons could have major influences on the propagation of seizure activity throughout the DG as occurs in temporal lobe epilepsy, but whether activity of MCs enhances or limits seizure activity remains a critical question (Sloviter et al., 2003; Ratzliff et al., 2004). To address this, Bui et al. (2018) used optogenetic methods to modulate the activity of remaining MCs in a chronic model of epilepsy. Photostimulation of MCs decreased the number of seizures that progressed from electrographic to generalized seizures, suggesting that their activation primarily inhibited distant dentate granule cells through disynaptic connections (Bui et al., 2018). The effects appeared to be related to the longitudinal projections of MCs as direct optogenetic inhibition of granule cells failed to limit the propagation, possibly because of their more lamellar circuitry.

A different perspective is provided by a recent study of MCs during an initial period of status epilepticus. Botterill et al. (2019) demonstrated that the direct excitatory effects of MCs on granule cells increased substantially during status epilepticus, and it is likely that these excitatory effects were propagated longitudinally throughout the DG. Selective chemogenetic reduction of MC activity during status epilepticus decreased CA3 and MC loss and blunted seizure activity during the chronic period (Botterill et al., 2019). These findings demonstrate the potential for strong excitatory and epileptogenic effects at MC to granule cell connections under some pathologic conditions and emphasize the multifaceted effects of MCs in epilepsy.

\section{Continuing challenges of dentate MCs}

Many questions have been raised regarding the function of MCs, including whether these neurons exert predominantly excitatory or inhibitory effects on granule cells. The current findings also suggest a need to consider the differential functions of dorsal and ventral MCs and their multiple pathways. Fortunately, tools are now available for studying MCs selectively in vivo and addressing many of these issues, with increased attention focused on the extensive longitudinal projections of MCs and their effects at distant sites within the DG.

\section{References}

Amaral DG (1978) A Golgi study of cell types in the hilar region of the hippocampus in the rat. J Comp Neurol 182:851-914. 
Amaral DG, Witter MP (1989) The three-dimensional organization of the hippocampal formation: a review of anatomical data. Neuroscience 31:571-591.

Bannerman DM, Rawlins JN, McHugh SB, Deacon RM, Yee BK, Bast T, Zhang WN, Pothuizen HH, Feldon J (2004) Regional dissociations within the hippocampus-memory and anxiety. Neurosci Biobehav Rev 28:273283.

Bienkowski MS, Bowman I, Song MY, Gou L, Ard T, Cotter K, Zhu M, Benavidez NL, Yamashita S, Abu-Jaber J, Azam S, Lo D, Foster NN, Hintiryan H, Dong HW (2018) Integration of gene expression and brainwide connectivity reveals the multiscale organization of mouse hippocampal networks. Nat Neurosci 21:1628-1643.

Blasco-Ibáñez JM, Freund TF (1997) Distribution, ultrastructure, and connectivity of calretinin-immunoreactive mossy cells of the mouse dentate gyrus. Hippocampus 7:307-320.

Botterill JJ, Lu YL, LaFrancois JJ, Bernstein HL, Alcantara-Gonzalez D, Jain S, Leary P, Scharfman HE (2019) An excitatory and epileptogenic effect of dentate gyrus mossy cells in a mouse model of epilepsy. Cell Rep 29:2875-2889.e6.

Brandt MD, Jessberger S, Steiner B, Kronenberg G, Reuter K, Bick-Sander A, von der Behrens W, Kempermann G (2003) Transient calretinin expression defines early postmitotic step of neuronal differentiation in adult hippocampal neurogenesis of mice. Mol Cell Neurosci 24:603-613.

Buckmaster PS, Schwartzkroin PA (1994) Hippocampal mossy cell function: a speculative view. Hippocampus 4:393-402.

Buckmaster PS, Wenzel HJ, Kunkel DD, Schwartzkroin PA (1996) Axon arbors and synaptic connections of hippocampal mossy cells in the rat in vivo. J Comp Neurol 366:271-292.

Bui AD, Nguyen TM, Limouse C, Kim HK, Szabo GG, Felong S, Maroso M, Soltesz I (2018) Dentate gyrus mossy cells control spontaneous convulsive seizures and spatial memory. Science 359:787-790.

Buzsàki G, Eidelberg E (1981) Commissural projection to the dentate gyrus of the rat: evidence for feed-forward inhibition. Brain Res 230:346-350.

Chancey JH, Poulsen DJ, Wadiche JI, Overstreet-Wadiche L (2014) Hilar mossy cells provide the first glutamatergic synapses to adult-born dentate granule cells. J Neurosci 34:2349-2354.

Danielson NB, Turi GF, Ladow M, Chavlis S, Petrantonakis PC, Poirazi P, Losonczy A (2017) In vivo imaging of dentate gyrus mossy cells in behaving mice. Neuron 93:552-559.e4.

Deller T, Nitsch R, Frotscher M (1995) Phaseolus vulgaris-leucoagglutinin tracing of commissural fibers to the rat dentate gyrus: evidence for a previously unknown commissural projection to the outer molecular layer. J Comp Neurol 352:55-68.

Deller T, Drakew A, Frotscher M (1999) Different primary target cells are important for fiber lamination in the fascia dentata: a lesson from reeler mutant mice. Exp Neurol 156:239-253.

Douglas RM, McNaughton BL, Goddard GV (1983) Commissural inhibition and facilitation of granule cell discharge in fascia dentata. J Comp Neurol 219:285-294.

Duffy AM, Schaner MJ, Chin J, Scharfman HE (2013) Expression of c-fos in hilar mossy cells of the dentate gyrus in vivo. Hippocampus 23:649-655.

Fanselow MS, Dong HW (2010) Are the dorsal and ventral hippocampus functionally distinct structures? Neuron 65:7-19.

Fredes F, Silva MA, Koppensteiner P, Kobayashi K, Joesch M, Shigemoto R (2020) Ventro-dorsal hippocampal pathway gates novelty-induced contextual memory formation. Curr Biol. Advance online publication. Retrieved Oct 13, 2020. doi:10.1016/j.cub.2020.09.074.

Fricke R, Cowan WM (1978) An autoradiographic study of the commissural and ipsilateral hippocampo-dentate projections in the adult rat. J Comp Neurol 181:253-270.

Frotscher M, Seress L, Schwerdtfeger WK, Buhl E (1991) The mossy cells of the fascia dentata: a comparative study of their fine structure and synaptic connections in rodents and primates. J Comp Neurol 312:145-163.

Fuentes-Santamaria V, Alvarado JC, Taylor AR, Brunso-Bechtold JK, Henkel CK (2005) Quantitative changes in calretinin immunostaining in the cochlear nuclei after unilateral cochlear removal in young ferrets. J Comp Neurol 483:458-475.

Fujise N, Liu Y, Hori N, Kosaka T (1998) Distribution of calretinin immunoreactivity in the mouse dentate gyrus: II. Mossy cells, with special reference to their dorsoventral difference in calretinin immunoreactivity. Neuroscience 82:181-200.
Gangarossa G, Longueville S, De Bundel D, Perroy J, Hervé D, Girault JA, Valjent E (2012) Characterization of dopamine D1 and D2 receptorexpressing neurons in the mouse hippocampus. Hippocampus 22:21992207.

Gong S, Zheng C, Doughty ML, Losos K, Didkovsky N, Schambra UB, Nowak NJ, Joyner A, Leblanc G, Hatten ME, Heintz N (2003) A gene expression atlas of the central nervous system based on bacterial artificial chromosomes. Nature 425:917-925.

GoodSmith D, Chen X, Wang C, Kim SH, Song H, Burgalossi A, Christian KM, Knierim JJ (2017) Spatial representations of granule cells and mossy cells of the dentate gyrus. Neuron 93:677-690.e5.

GoodSmith D, Lee H, Neunuebel JP, Song H, Knierim JJ (2019) Dentate gyrus mossy cells share a role in pattern separation with dentate granule cells and proximal CA3 pyramidal cells. J Neurosci 39:9570-9584.

Gottlieb DI, Cowan WM (1973) Autoradiographic studies of the commissural and ipsilateral association connections of the hippocampus and detentate gyrus of the rat. I. The commissural connections. J Comp Neurol 149:393-422.

Hashimotodani Y, Nasrallah K, Jensen KR, Chávez AE, Carrera D, Castillo PE (2017) LTP at hilar mossy cell-dentate granule cell synapses modulates dentate gyrus output by increasing excitation/inhibition balance. Neuron 95:928-943.e3.

Hetherington PA, Austin KB, Shapiro ML (1994) Ipsilateral associational pathway in the dentate gyrus: an excitatory feedback system that supports $\mathrm{N}$-methyl-D-aspartate-dependent long-term potentiation. Hippocampus 4:422-438.

Houser CR, Peng Z, Huang CS, Wei X, Mody I (2019) Mossy cells in the rostral and caudal dentate gyrus differ in their patterns of axonal projections. 2019 Neuroscience Meeting Planner, Chicago: Society for Neuroscience.

Hsu TT, Lee CT, Tai MH, Lien CC (2016) Differential recruitment of dentate gyrus interneuron types by commissural versus perforant pathways. Cereb Cortex 26:2715-2727.

Jiao Y, Nadler JV (2007) Stereological analysis of GluR2-immunoreactive hilar neurons in the pilocarpine model of temporal lobe epilepsy: correlation of cell loss with mossy fiber sprouting. Exp Neurol 205:569-582.

Jinde S, Zsiros V, Jiang Z, Nakao K, Pickel J, Kohno K, Belforte JE, Nakazawa K (2012) Hilar mossy cell degeneration causes transient dentate granule cell hyperexcitability and impaired pattern separation. Neuron 76:11891200.

Jinno S, Ishizuka S, Kosaka T (2003) Ionic currents underlying rhythmic bursting of ventral mossy cells in the developing mouse dentate gyrus. Eur J Neurosci 17:1338-1354.

Jung D, Kim S, Sariev A, Sharif F, Kim D, Royer S (2019) Dentate granule and mossy cells exhibit distinct spatiotemporal responses to local change in a one-dimensional landscape of visual-tactile cues. Sci Rep 9:9545.

Kheirbek MA, Drew LJ, Burghardt NS, Costantini DO, Tannenholz L, Ahmari SE, Zeng H, Fenton AA, Hen R (2013) Differential control of learning and anxiety along the dorsoventral axis of the dentate gyrus. Neuron 77:955-968.

Kleschevnikov AM, Routtenberg A (2003) Long-term potentiation recruits a trisynaptic excitatory associative network within the mouse dentate gyrus. Eur J Neurosci 17:2690-2702.

Laurberg S, Sørensen KE (1981) Associational and commissural collaterals of neurons in the hippocampal formation (hilus fasciae dentatae and subfield CA3). Brain Res 212:287-300.

Leranth C, Szeidemann Z, Hsu M, Buzsáki G (1996) AMPA receptors in the rat and primate hippocampus: a possible absence of GluR2/3 subunits in most interneurons. Neuroscience 70:631-652.

Liu Y, Fujise N, Kosaka T (1996) Distribution of calretinin immunoreactivity in the mouse dentate gyrus. I. General description. Exp Brain Res 108:389-403.

Moretto JN, Duffy ÁM, Scharfman HE (2017) Acute restraint stress decreases c-fos immunoreactivity in hilar mossy cells of the adult dentate gyrus. Brain Struct Funct 222:2405-2419.

Nakazawa K (2017) Dentate mossy cell and pattern separation. Neuron 93:465-467.

Paxinos G, Franklin K (2019) Paxinos and Franklin's the mouse brain in stereotaxic coordinates, Ed 5. New York: Academic Press.

Peng Z, Zhang N, Wei W, Huang CS, Cetina Y, Otis TS, Houser CR (2013) A reorganized GABAergic circuit in a model of epilepsy: evidence from optogenetic labeling and stimulation of somatostatin interneurons. J Neurosci 33:14392-14405. 
Petralia RS, Wang YX, Mayat E, Wenthold RJ (1997) Glutamate receptor subunit 2-selective antibody shows a differential distribution of calciumimpermeable AMPA receptors among populations of neurons. J Comp Neurol 385:456-476.

Puighermanal E, Biever A, Espallergues J, Gangarossa G, De Bundel D, Valjent E (2015) Drd2-cre:ribotag mouse line unravels the possible diversity of dopamine $\mathrm{d} 2$ receptor-expressing cells of the dorsal mouse hippocampus. Hippocampus 25:858-875.

Ratzliff AH, Howard AL, Santhakumar V, Osapay I, Soltesz I (2004) Rapid deletion of mossy cells does not result in a hyperexcitable dentate gyrus: implications for epileptogenesis. J Neurosci 24:2259-2269.

Sans N, Vissel B, Petralia RS, Wang YX, Chang K, Royle GA, Wang CY, O'Gorman S, Heinemann SF, Wenthold RJ (2003) Aberrant formation of glutamate receptor complexes in hippocampal neurons of mice lacking the GluR2 AMPA receptor subunit. J Neurosci 23:9367-9373.

Scharfman HE (1995) Electrophysiological evidence that dentate hilar mossy cells are excitatory and innervate both granule cells and interneurons. J Neurophysiol 74:179-194.

Scharfman HE (2007) The CA3 "backprojection" to the dentate gyrus. Prog Brain Res 163:627-637.

Scharfman HE (2016) The enigmatic mossy cell of the dentate gyrus. Nat Rev Neurosci 17:562-575.

Senzai Y, Buzsáki G (2017) Physiological properties and behavioral correlates of hippocampal granule cells and mossy cells. Neuron 93:691-704.e5.

Sloviter RS, Lømo T (2012) Updating the lamellar hypothesis of hippocampal organization. Front Neural Circuits 6:102.

Sloviter RS, Zappone CA, Harvey BD, Bumanglag AV, Bender RA, Frotscher M (2003) Dormant basket cell hypothesis revisited: relative vulnerabilities of dentate gyrus mossy cells and inhibitory interneurons after hippocampal status epilepticus in the rat. J Comp Neurol 459:44-76.

Strange BA, Witter MP, Lein ES, Moser EI (2014) Functional organization of the hippocampal longitudinal axis. Nat Rev Neurosci 15:655-669.
Swanson LW, Wyss JM, Cowan WM (1978) An autoradiographic study of the organization of intrahippocampal association pathways in the rat. J Comp Neurol 181:681-716.

van Groen T, Miettinen P, Kadish I (2003) The entorhinal cortex of the mouse: organization of the projection to the hippocampal formation. Hippocampus 13:133-149.

Weeden CS, Roberts JM, Kamm AM, Kesner RP (2015) The role of the ventral dentate gyrus in anxiety-based behaviors. Neurobiol Learn Mem 118:143-149.

Wenzel HJ, Buckmaster PS, Anderson NL, Wenzel ME, Schwartzkroin PA (1997) Ultrastructural localization of neurotransmitter immunoreactivity in mossy cell axons and their synaptic targets in the rat dentate gyrus. Hippocampus 7:559-570.

Williams PA, Larimer P, Gao Y, Strowbridge BW (2007) Semilunar granule cells: glutamatergic neurons in the rat dentate gyrus with axon collaterals in the inner molecular layer. J Neurosci 27:13756-13761.

Witter MP (2007) The perforant path: projections from the entorhinal cortex to the dentate gyrus. Prog Brain Res 163:43-61.

Woods NI, Vaaga CE, Chatzi C, Adelson JD, Collie MF, Perederiy JV, Tovar KR, Westbrook GL (2018) Preferential targeting of lateral entorhinal inputs onto newly integrated granule cells. J Neurosci 38:5843-5853.

Yeh CY, Asrican B, Moss J, Quintanilla LJ, He T, Mao X, Cassé F, Gebara E, Bao H, Lu W, Toni N, Song J (2018) Mossy cells control adult neural stem cell quiescence and maintenance through a dynamic balance between direct and indirect pathways. Neuron 99:493-510.e4.

Zappone CA, Sloviter RS (2004) Translamellar disinhibition in the rat hippocampal dentate gyrus after seizure-induced degeneration of vulnerable hilar neurons. J Neurosci 24:853-864.

Zimmer J (1971) Ipsilateral afferents to the commissural zone of the fascia dentata, demonstrated in decommissurated rats by silver impregnation. J Comp Neurol 142:393-416. 